\title{
Observations of Typhoon Waves in a Reef Lagoon of the South China Sea
}

\author{
Z. W. CAI \\ Department of Offshore Structures, China Ship Scientific Research Center, Wuxi, China \\ W. W. CHEN \\ Shanghai Branch, China Ship Scientific Research Center, Shanghai, China \\ X. L. LIU AND Z. SUN \\ Department of Offshore Structures, China Ship Scientific Research Center, Wuxi, China
}

(Manuscript received 28 June 2019, in final form 27 October 2019)

\begin{abstract}
Based on wave measurements lasting three and a half years, typhoon wave characteristics in a lagoon of the South China Sea are discussed in this paper. According to the upper boundaries of wind speed and significant wave height $H_{s}$, the maximum wave height has a similar rate of change as the maximum wind speed. The peak frequencies decrease in the approaching stage and are concentrated with an average of $0.1415 \mathrm{~Hz}$ in the leaving stage. The distributions of the wind and wave directions indicate that the local wind waves and the waves from the open sea propagated to the site in the approaching and leaving stages, respectively. Wind waves generated inside the lagoon are fetch-trapped, and the spectra can be described by $\alpha f^{(-4)}$ or $\beta k^{(-2.5)}$ when $f>f_{p}$. In addition, the measurements show that the nondimensional maximum spectrum can be estimated by the nondimensional fetch. The spectra of the waves from the open sea can be described by $a f_{p}^{(c-b)} f^{(b)}$. Parameters $a$ and $c$ are determined by the nondimensional peak frequency. In addition, it is found that the peak energy density $S\left(f_{p}\right)$ is a linear function of $g^{-1 / 2} H_{s}^{5 / 2}$ for all waves.
\end{abstract}

\section{Introduction}

In the South China Sea (SCS), typhoons happen very frequently, 15 times yearly from 1961 to 2010 (Hong Kong Observatory 2015). The intense winds generate large and potentially destructive waves.

The investigation of typhoon waves started in the 1930s (Tannehill 1936). The most fascinating studies were carried out by Donelan et al. (1985), Young (1988, 1998, 1999, 2006, 2017), and Young and Vinoth (2013). A relationship between nondimensional wave energy and nondimensional peak frequency was proposed by Donelan et al. (1985) for fetch-limited waves, which can also be applied to typhoon waves (Young 2017). Further research was implemented by Young $(1988,1998,1999,2006,2017)$ and Young and Vinoth (2013), who defined the "fetch" for typical typhoon fields and studied typhoon waves from every side. Other scholars have also made contributions to

\footnotetext{
Corresponding author: Z. W. Cai, caizhiwen0904@163.com
}

the understanding of typhoon waves. Those were addressed by Young (2017).

A key advance in understanding typhoon waves was made based on airborne data. King and Shemdin (1978) indicated that waves tended to radiate out from intense wind regions to the right of the storm center (Young 2017). Based on the data of Wright et al. (2001), Black et al. (2007) divided the wave field into three azimuthal sectors: the right front sector, the left front sector and the rear sector. This approach has been employed to study the distribution of drag coefficients by Powell (2007) and Holthuijsen et al. (2012). Similar sectors have also been used to establish the effective fetch by Hwang and Wang (2004). Recently, Hwang and his collaborators argued that wave development inside typhoon follows essentially the same durationand fetch-limited growth functions established in steady wind, and effective fetch and duration models were formulated for these waves (Hwang 2016; Hwang and Walsh 2016; Hwang and Fan 2017). The direction wave spectrum acquired by an airborne scanning radar altimeter 


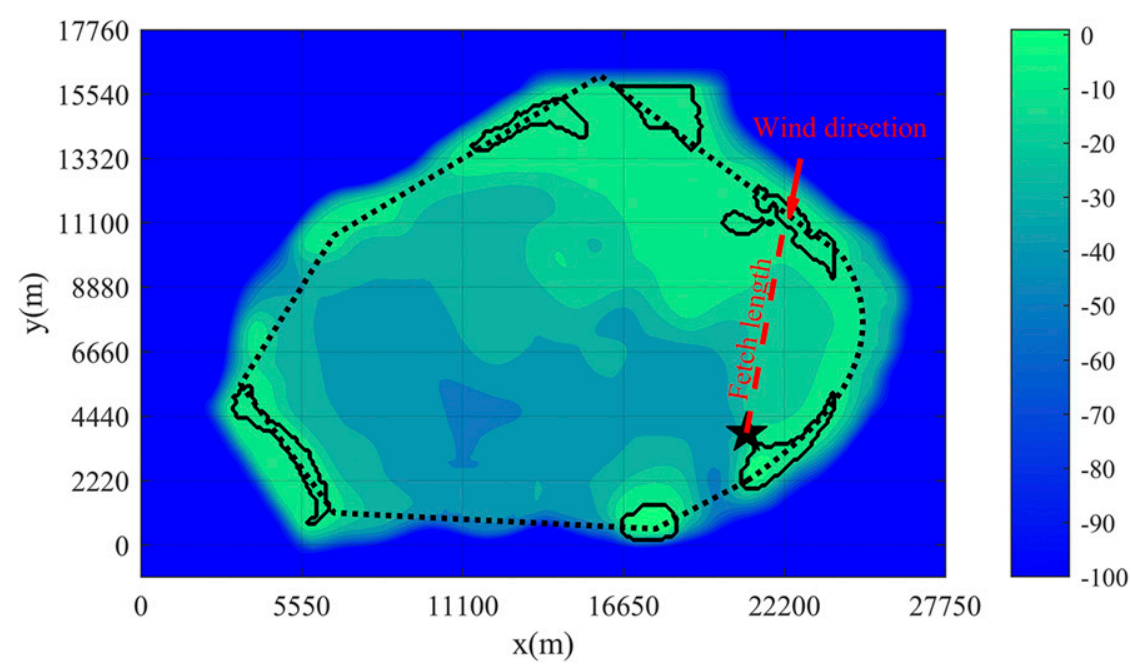

FIG. 1. Layout of instrument and topography. The lagoon is surrounded by the ocean. The outlines of the islands are given by black solid lines. The outline of the lagoon is expressed by dotted lines, which are employed to calculate the fetch length. The star denotes the location of the instrument. An example of how to calculate the fetch length is drawn by the red dashed line, and the wind direction is shown by the red arrow.

was also compared with wind-wave models by Hwang et al. (2017).

In recent years, the study of typhoon waves in the SCS has been a hot topic. Buoy-based observations of three typhoon waves in the SCS were utilized to obtain the wave characteristics by Xu et al. (2017). Measurement spectra were studied by Shi et al. (2017) and Ren et al. (2014). Numerical studies have also been employed for typhoon waves by Chu and Cheng (2008) and Chu et al. (2004).

However, the above studies focused on waves in the open sea. Waves in reef lagoons are meaningful in coral reef protection and ocean structure design (Ding et al. 2017; Wu et al. 2018). Because of the complicated topography, waves inside a lagoon are quite different from those in the open sea. In some cases, waves generated from the right of a typhoon eye may be shielded by reefs and islands, and local wind waves dominate the lagoon. In other cases, the lagoon is dominated by waves from the open sea. These waves are reduced due to the roughness and steep slope of the reef (Cai et al. 2019; Cheriton et al. 2016; Gallop et al. 2014; Gourlay 1994; Huang et al. 2012; Kench and Brander 2006; Lentz et al. 2016; Liu et al. 2019; Lowe et al. 2005; Monismith et al. 2013, 2015; Péquignet et al. 2011). Unfortunately, typhoon waves in lagoons are rarely studied owing to limited measurement data.

In this paper, the characteristics of waves in a lagoon are estimated in detail for seven typhoon waves. This paper is organized as follows. In section 2, an overall description of the in situ experiment and typhoons is presented. Analysis of wind and wave parameters is given in section 3. The wind-wave relationship is presented in section 4 and the one-dimensional spectrum is studied in section 5. Finally, the conclusions are drawn.

\section{Experimental setup and information of typhoons}

\section{a. Experimental setup}

An experiment from June 2014 to September 2017 was conducted in a reef lagoon surrounded by the ocean, as shown in Fig. 1. The depth of the measurement site is approximately $25 \mathrm{~m}$, and the average depth of the lagoon is approximately $30 \mathrm{~m}$.

A Datawell DWR-MkIII directional Waverider buoy (DWR MKIII) was moored at the site in July 2014. This buoy was broken in June 2016 and replaced with an acoustic wave and current (AWAC) profiler produced by Nortek. It took us a year to repair the buoy. On 25 July 2017, the buoy was redeployed, and the AWAC profiler was salvaged. Information for these two instruments is given in Table 1.

Fast Fourier transforms (FFTs) of heavy, north and east displacements are employed by the software of the Waverider to obtain the wave spectrum and parameters (Datawell 2006). The accuracy of this buoy has been verified through comparisons with fixed platform array measurements of Pacific swell (Herbers et al. 2009) and the long linear array at the Field Research Facility (FRF; Luther et al. 2013).

The central method of the AWAC wave measurement is the acoustic surface tracking (AST) method. Based on 
TABLE 1. Deployment details for the Waverider and AWAC profiler.

\begin{tabular}{lcc}
\hline \multicolumn{1}{c}{ Parameter } & DWR MKIII & 600 kHz 4-beam AWAC profiler \\
\hline Deployment period & June 2014-June 2016, & June 2016-25 July 2017 \\
Burst interval & 25 July 2017-September 2017 & Approximately 17.1 min \\
Output sampling frequency (Hz) & $30 \mathrm{~min}$ & 1 for current \\
& 1.28 & 2 for AST \\
Length of processed time series per burst & 2304 & 1024 \\
Low cutoff frequency (Hz) & 0.025 & 0.01 \\
High cutoff frequency (Hz) & 0.58 & 0.99 for AST and one-dimensional \\
& & spectrum 0.49 for directional spectrum \\
\hline
\end{tabular}

this method, the distance to the surface is directly estimated by the vertically oriented transducer in the center of the AWAC profiler, which means a time series of the sea surface elevation is available to calculate the nondirectional spectrum and parameters (Lohrmann et al. 2011). Additionally, the wave direction is estimated by using several measurements of orbital velocity together with AST (Lohrmann et al. 2011). The AWAC data are processed by Storm software, where AST is included in the maximum likelihood method (MLM) to improve upon the accuracy of the directional estimates. Previous comparisons with buoys showed that the AWAC profiler, in the configuration used here, provides reliable wave parameters and the one-dimensional spectrum (Pedersen and Lohrmann 2004; Pedersen et al. 2006; Smith et al. 2013).

Wind data from Sanhu Dao station are employed to study the relationship between wind and wave and are collected from the integrated surface database (ISD; Smith et al. 2011).

\section{b. Data}

In this paper, we focus on the wave parameters and one-dimensional spectrum. The one-dimensional spectrum is calculated by the FFT (buoy) or MLM (AWAC). The peak frequency $f_{p}$ is the frequency associated with the maximum peak in the spectrum. The generally accepted approximation of significant wave height $H_{s}$ is

$$
H_{s}=4.0 \sqrt{\int S(f) d f} .
$$

The direction is estimated by the cross-spectrum of sea surface elevation and displacement (buoy) or current velocity (AWAC), and the peak wave direction is the mean direction associated with the maximum peak in the one-dimensional spectrum. Note that wave directions are always reported as the direction where the waves are coming from.

Winds are transferred into $10-\mathrm{m}$ elevated winds by the following "log law":

$$
\mathrm{Ws}=U_{\mathrm{raw}} \frac{\ln \left(10 / z_{*}\right)}{\ln \left(z_{0} / z_{*}\right)}
$$

where $z *$ is the aerodynamic roughness length, $z_{0}=5 \mathrm{~m}$ is the elevation of the Sanhu Dao station, and $U_{\text {raw }}$ is the raw wind speed. The wind directions are always reported as the direction where the wind is coming from.

The samples are selected by the following criteria:

1) The distance between the site and the typhoon center ( $\left.L_{\mathrm{ts}}\right)$ is less than $20 R_{\max }$, where $R_{\max }$ is the radius of the maximum wind speed.

2) Most of the wind speeds are greater than $5 \mathrm{~m} \mathrm{~s}^{-1}$.

A total of 145 samples with 3-h intervals were selected according to the typhoon information and the criteria above.

\section{c. Information of typhoons}

Seven typhoons-Kalmaegi (1415), Kujira (1508), Dianmu (1608), Sarika (1621), Talas (1704), Sonca (1708), and Doksuri (1719)—are selected because each caused serious sea conditions at the measurement site. All of these typhoons moved toward the west or northwest. The waves during Typhoon Kalmaegi in the open sea were studied by Xu et al. (2017), and those in the lagoon were numerically studied by Sun et al. (2019). The typhoon details are obtained from the Joint Typhoon Warning Center (JTWC). The best tracks (BST) are shown in Fig. 2, and some information is given in Table 2.

The best tracks are also presented in "typhoon coordinates" in Fig. 3. In typhoon coordinates, the typhoon eye is located at the origin and is translating north. The radius and angle are defined as

$$
\begin{aligned}
& r=\frac{L_{\mathrm{ts}}}{R_{\max }}, \\
& \theta=\theta_{\mathrm{ts}}-\theta_{t},
\end{aligned}
$$

where $L_{\mathrm{ts}}$ is the distance between the typhoon center and the site, $R_{\max }$ is the radius of the maximum wind 

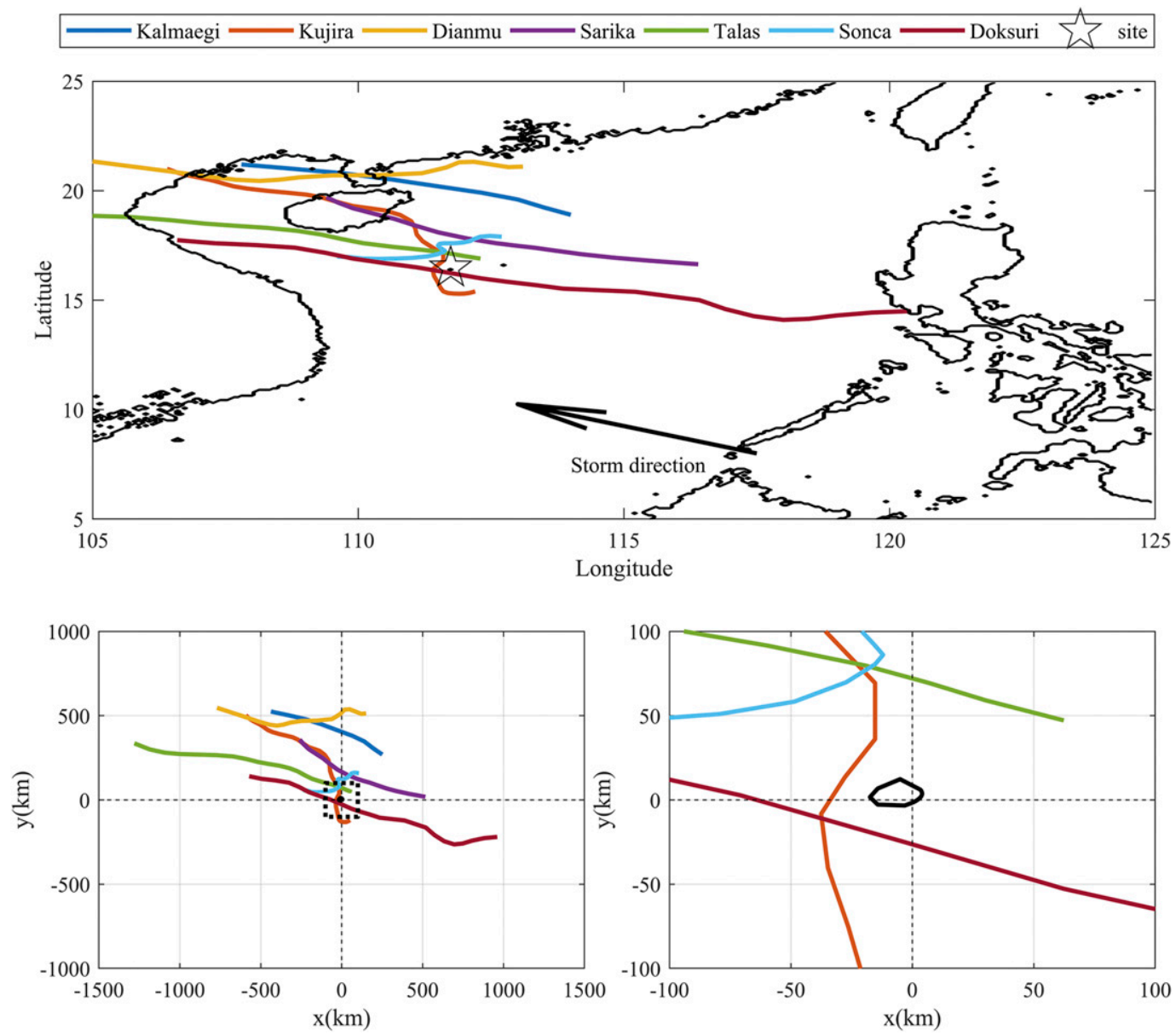

FIG. 2. The best tracks of typhoons (BST) in the study period. (top) The best tracks in the map, where the star denotes the location of the reef lagoon; (bottom left) the best tracks, where the site is located at the origin and (bottom right) detailed BSTs in the region selected by the dotted lines in the bottom-left image. The outline of the lagoon is drawn in black lines. The direction of typhoons is drawn by the black arrow.

speed, $\theta_{\mathrm{ts}}$ is the direction that points forward from the typhoon to the site, and $\theta_{t}$ is the storm direction.

Furthermore, the nondimensional time is also employed to study the wave characteristics as follows:

$$
\tau=\frac{t-t_{0}}{T_{0}}
$$

where $t_{0}$ is the time when the typhoon center is closest to the measurement site, and $T_{0}$ is the inertial period related to the latitude of the measurement site. Among the 145 samples, 56 and 89 samples occurred in the typhoon approaching stage $(\tau \leq 0)$ and the typhoon leaving stage $(\tau>0)$, respectively.

Figure 3 also shows three azimuthal sectors inferred from Holthuijsen et al. (2012). We thus find that most of the waves in the approaching stage are located in the left and right front sectors, while those in the leaving stage are located in the rear sector.

\section{Wave characteristics}

a. Wind speed Ws, significant wave height $H_{s}$, and peak frequency $f_{p}$

The distributions of Ws and $H_{s}$ are given in Fig. 4. The 145 samples are divided into 28 groups by $\tau$ as follows:

$$
\begin{aligned}
& -1.5<\tau \leq-1.375, \quad-1.375<\tau \leq-1.25, \ldots, \\
& 1.875<\tau \leq 2 .
\end{aligned}
$$

The maximum values of each group can be fitted by

$$
\begin{aligned}
\mathrm{Ws}^{\max } & =\left\{\begin{array}{ll}
5.842(\tau+2)^{2.11}, & -1.5<\tau<0.142 \\
12.30 \tau^{-0.46}, & 0.142 \leq \tau<2
\end{array},\right. \\
H_{s}^{\max } & = \begin{cases}0.336(\tau+2)^{2.74}, & -1.5<\tau<0.142 \\
1.175 \tau^{-0.44}, & 0.142 \leq \tau<2\end{cases}
\end{aligned}
$$


TABLE 2. Information on the typhoons.

\begin{tabular}{|c|c|c|c|c|c|}
\hline \multirow{2}{*}{$\begin{array}{l}\text { Annual } \\
\text { cyclone } \\
\text { number }\end{array}$} & \multirow[b]{2}{*}{ Name } & \multirow{2}{*}{$\begin{array}{l}\text { Minimum center } \\
\text { pressure over } \\
\text { life }(\mathrm{hPa})\end{array}$} & \multicolumn{2}{|c|}{ Study period time and criteria } & \multirow[b]{2}{*}{ Sample number } \\
\hline & & & Start time and criterion & End time and criterion & \\
\hline \multirow[t]{2}{*}{1415} & \multirow[t]{2}{*}{ Kalmaegi } & \multirow[t]{2}{*}{963} & 1200 UTC 15 Sep 2014 & 1200 UTC 16 Sep 2014 & \multirow[t]{2}{*}{9} \\
\hline & & & $\begin{array}{l}\text { Waves before } 1200 \text { UTC } \\
\text { were lost }\end{array}$ & The end time of BST & \\
\hline \multirow[t]{2}{*}{1508} & \multirow[t]{2}{*}{ Kujira } & \multirow[t]{2}{*}{985} & 0000 UTC 20 Jun 2014 & 1200 UTC 24 Jun 2015 & \multirow[t]{2}{*}{37} \\
\hline & & & The start time of BST & The end time of BST & \\
\hline \multirow[t]{2}{*}{1608} & \multirow[t]{2}{*}{ Dianmu } & \multirow[t]{2}{*}{989} & 1200 UTC 17 Aug 2016 & 1200 UTC 19 Aug 2016 & \multirow[t]{2}{*}{17} \\
\hline & & & The start time of BST & $L_{\mathrm{ts}}<5 R_{\max }$ & \\
\hline \multirow[t]{2}{*}{1621} & \multirow[t]{2}{*}{ Sarika } & \multirow[t]{2}{*}{963} & 1500 UTC 16 Oct 2016 & 1200 UTC 18 Oct 2016 & \multirow[t]{2}{*}{16} \\
\hline & & & $L_{\mathrm{ts}}<5 R_{\max }$ & $\mathrm{Ws}>5 \mathrm{~ms}^{-1}$ & \\
\hline \multirow[t]{2}{*}{1704} & \multirow[t]{2}{*}{ Talas } & \multirow[t]{2}{*}{985} & 0000 UTC 15 Jul 2017 & 1200 UTC 17 Jul 2017 & \multirow[t]{2}{*}{21} \\
\hline & & & The start time of BST & The end time of BST & \\
\hline \multirow[t]{2}{*}{1708} & \multirow[t]{2}{*}{ Sonca } & \multirow[t]{2}{*}{996} & 0000 UTC 22 Jul 2017 & 1800 UTC 24 Jul 2017 & \multirow[t]{2}{*}{23} \\
\hline & & & $\mathrm{Ws}>5 \mathrm{~ms}^{-1}$ & $\mathrm{Ws}>5 \mathrm{~ms}^{-1}$ & \\
\hline \multirow[t]{2}{*}{1719} & \multirow[t]{2}{*}{ Doksuri } & \multirow[t]{2}{*}{960} & 1200 UTC 12 Sep 2017 & 0300 UTC 15 Sep 2017 & 22 \\
\hline & & & $\mathrm{Ws}>5 \mathrm{~ms}^{-1}$ & $\mathrm{Ws}>5 \mathrm{~m} \mathrm{~s}^{-1}$ & $\begin{array}{r}\text { (Waves of } 0600 \text { UTC } 13 \text { Sep and } \\
1200 \text { UTC } 13 \text { Sep } 2017 \text { were lost) }\end{array}$ \\
\hline
\end{tabular}

Clearly, the indexes of Eq. (6) are close to those of Eq. (7), which implies that the maximum wave height has a similar rate of change as the maximum wind speed.

The distribution of $f_{p}$ can be divided into two parts by $\tau=0$, as shown in Fig. 5. The peak frequencies are scattered and decrease with time when $\tau \leq 0$. When $\tau>0$, the peak frequencies are concentrated, and the average is $0.1415 \mathrm{~Hz}$.

\section{b. Wind direction and peak wave direction}

Following Zhang and Uhlhorn (2012) and Hwang et al. (2017), the wind and wave directions measured from the normal to the local position vector are given in Fig. 6.

Most of the observed winds veer toward the typhoon center (see Fig. 6), which is similar to the flow pattern around a vortex. This finding has been validated by Hwang et al. (2017) in the open sea.

In contrast to the wind direction, the wave directions given in Fig. 6 are more complex. In the front sector, most of the waves veer toward the typhoon center, and the following waves play the most important role. In the rear sector, the wave direction veers almost toward the outer edge of the typhoon, and the cross wave dominates the sector.

The time distributions of the wind direction and peak wave direction are also studied in Fig. 7. Both the wind directions and wave directions are concentrated around the north in the approaching stage $(\tau \leq 0)$. In the leaving stage $(\tau>0)$, south winds and west waves are common. In addition, the direction difference is sensitive to the
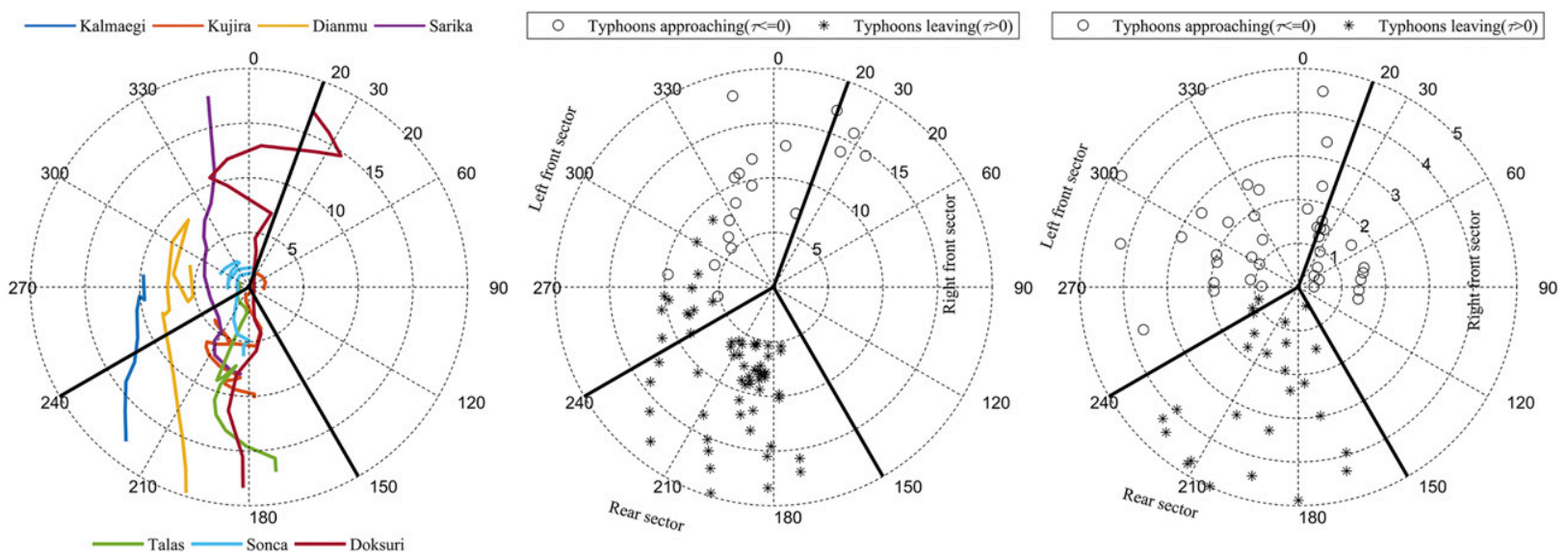

FIG. 3. The best tracks in typhoon coordinates. (left) The best tracks. (center) Data for $r=L_{\mathrm{ts}} / R_{\max }<5$. (right) Data for $r=L_{\mathrm{ts}} / R_{\mathrm{max}} \geq$ 5 . The boundaries of the azimuthal sectors are drawn by the black solid lines. The waves that occurred in the typhoon approaching and leaving stages are presented by the circles and the asterisks, respectively. 

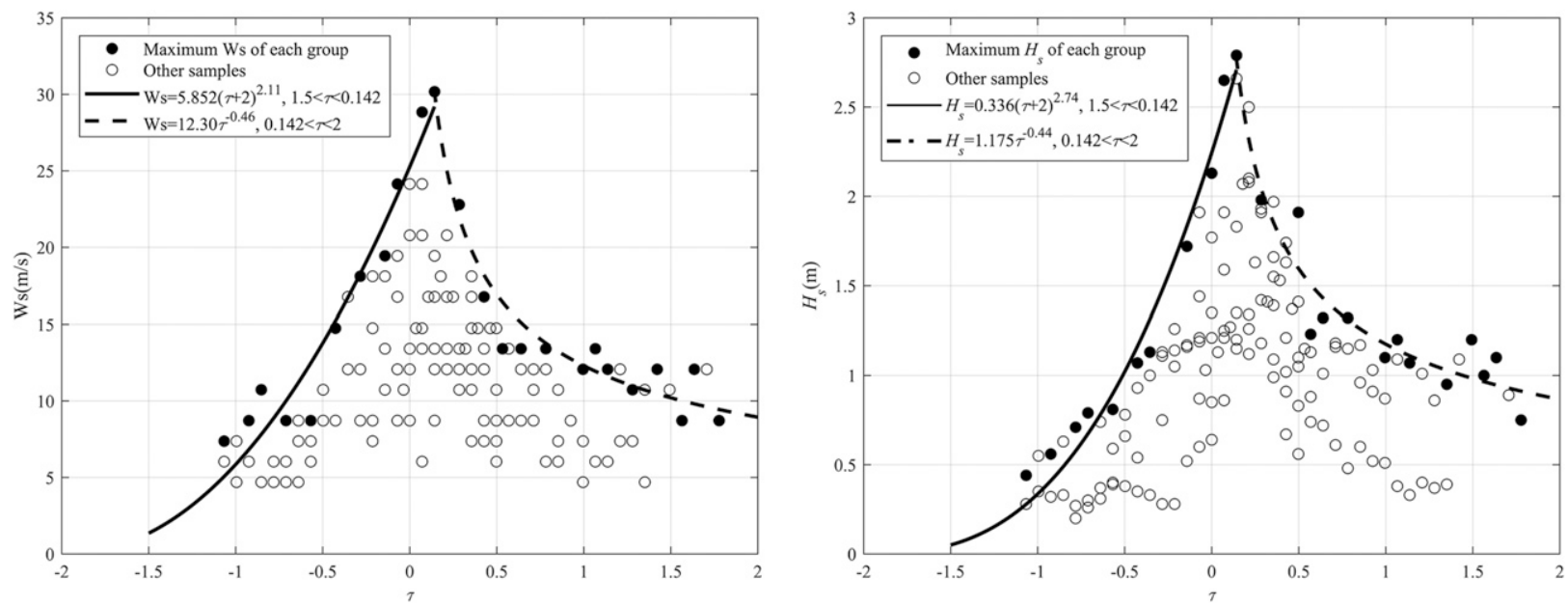

FIG. 4. Time distributions of wind speed and significant wave height $H_{s}$. The 145 samples are divided into 28 groups by $\tau$. The maximum values of these groups are drawn by solid circles and fitted by the solid and dashed lines.

nondimensional time. In the approaching and leaving stages, the field is dominated by the following waves and cross wave, respectively.

The results in the approaching stage (all of these waves are located in the left or right front sectors, see Fig. 3) are quite different from those in the open sea. In the open sea, the waves in the approaching stage are generated from the right of the typhoon eye at an earlier time. Based on the BST shown in Fig. 2, most of these waves should come from the east (Typhoon Doksuri) or northeast (other typhoons). However, it seems that these young waves were shielded by the reefs and islands in the northeast of the lagoon. As a result, the waves generated locally dominated the lagoon.

In the leaving stage (most of these waves are located in the rear sector, see Fig. 3), the wave directions are similar to those of waves in the open sea studied by Hwang et al. (2017). As the western lagoon is open to the outer sea, we suggest that waves in the leaving stage came from the open sea.

\section{Relationship between wind and waves}

According to the results of the previous section, the waves generated inside the lagoon and from the open sea propagated to the site in the approaching and leaving stages, respectively. In this section, the fetch-limited theory is validated using these waves.

\section{a. Approaching stage: Waves generated inside the lagoon}

In fetch-limited theory, $H_{s}$ and $f_{p}$ can be parameterized by (Young 1999)

$$
\begin{aligned}
& \varepsilon=7.5 \times 10^{-7} \chi^{0.8}, \\
& \nu=2.00 \chi^{-0.25,}
\end{aligned}
$$

and (Donelan et al. 1985)

$$
\varepsilon=6.365 \times 10^{-6} \nu^{-3.3},
$$

where

$$
\varepsilon=\frac{H_{s}^{2} g^{2}}{16 \mathrm{Ws}^{4}}, \quad \nu=\frac{\mathrm{Ws} f_{p}}{g}, \quad \text { and } \quad \chi=\frac{g x}{\mathrm{Ws}^{2}}
$$

are the nondimensional wave energy, peak frequency, and fetch, respectively. The fetch is calculated by the outlines of the lagoon, see Fig. 1. The good agreement

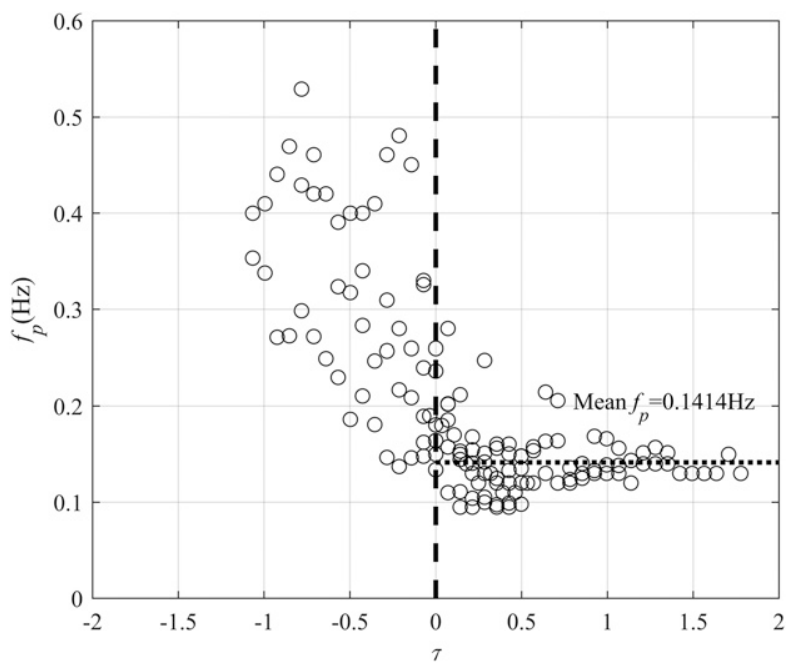

FIG. 5. Time distribution of peak frequency. 

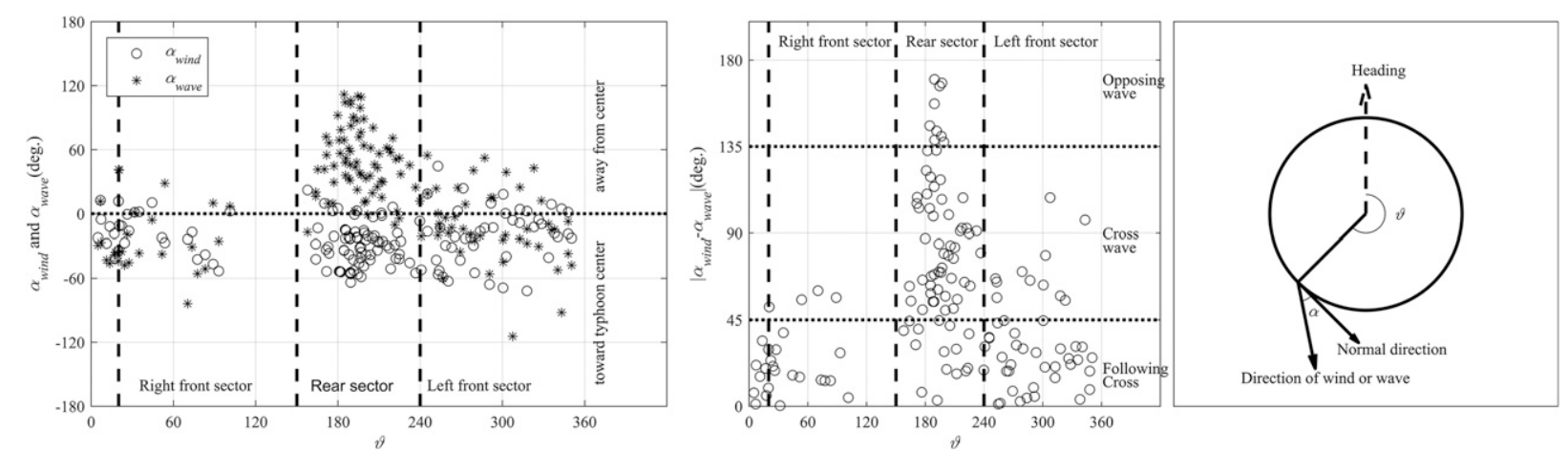

FIG. 6. Wind and wave directions measured from the normal to the local position vector plotted against the azimuth angle $\theta$. (left) Wind and wave directions. (center) The direction difference between wind and waves. (right) A sketch of the direction. Following Holthuijsen et al. (2012) we define a following wave as one that travels within $45^{\circ}$ of the wind direction, the cross wave as one that travels within $45^{\circ}$ of the normal to the wind direction, and the opposing wave as one that travels within $45^{\circ}$ of the opposing direction.

between the observations and the empirical relationship validates our conclusion that the waves were mostly generated in the lagoon (see Fig. 8).

\section{b. Leaving stage: Waves from the open sea}

In the open sea, the agreement between the data at all stages and the empirical relationship in Eq. (9) is remarkable (Young 2017). Observations in the lagoon are compared with Eq. (9) in Fig. 9. Obviously, the energies are overestimated for most waves. Fortunately, the observed data agree well with another empirical relationship (Fig. 9) as follows:

$$
\varepsilon=1.355 \times 10^{-5} \nu^{-1.9}
$$

Assuming that the open sea is dominated by wind waves, the energy dissipated by the reefs and islands at different frequencies can be determined by Eqs. (9) and (11). However, this equation is heavily dependent on the topography and the wave direction.

\section{One-dimensional spectrum}

\section{a. Approaching stage: Fetch-trapped waves generated inside the lagoon}

The nondimensional spectra are shown in Fig. 10. It is obvious that the spectra are of the form $\alpha f^{(-4)}$ when $f>$ $f_{p}$, which is known as the "equilibrium range" (Badulin et al. 2005; Long and Resio 2007; Zakharov et al. 2012). In deep water, the spectra in the equilibrium range can be expressed as (Resio et al. 2004):

$$
\begin{aligned}
& S(f)=\alpha \operatorname{Ws} g(2 \pi)^{-3} f^{-4}, \\
& \text { or } \\
& F(k)=\beta k^{-5 / 2},
\end{aligned}
$$

where Ws is the wind speed at a fixed reference level of $10 \mathrm{~m}$ above the mean water surface, and $\alpha$ and $\beta$ can be estimated by (Long and Resio 2007)

$$
\alpha=A_{\alpha} \chi^{n_{H}-3 n_{f}},
$$
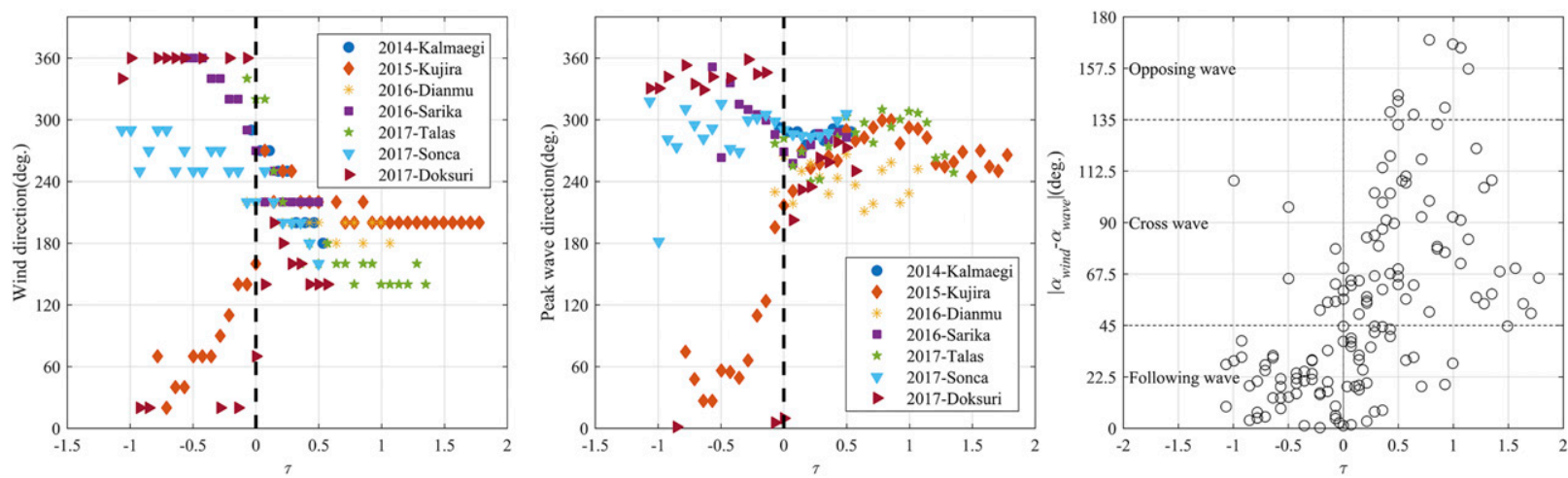

FIG. 7. Time distributions of wind direction and wave direction. (left) Wind direction. (center) Wave direction. (right) Directional difference, where $\operatorname{Dir}_{p}$ and $W_{d}$ are the peak wave and wind directions, respectively. 

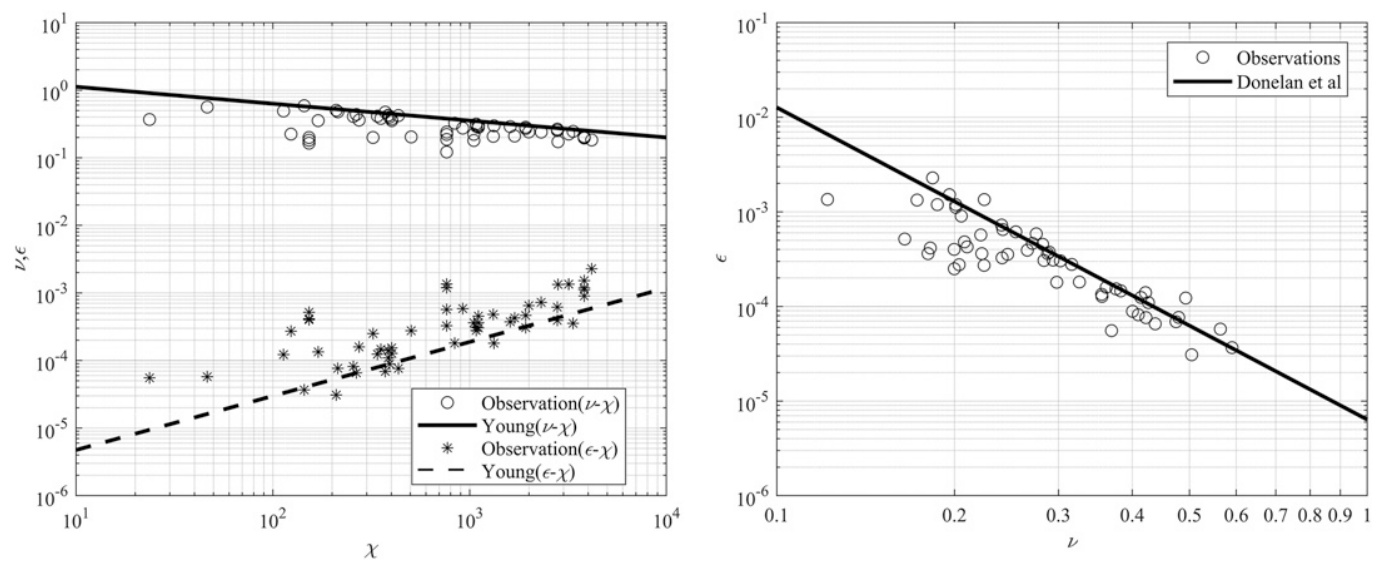

FIG. 8. Relationship between wind and waves in the approaching stage.

$$
\beta=\frac{1}{2} \beta_{0}\left[\left(\mathrm{Ws}^{2} c_{p}\right)^{1 / 3}-u_{0}\right] g^{-0.5}
$$

where $n_{H}$ and $n_{f}$ are the exponents in the power laws [Eq. (8)] for $\varepsilon$ and $\nu$, respectively. Parameter $c_{p}$ is the phase speed of the wave, and $\beta_{0}$ and $u_{0}$ are parameters. As shown in Fig. 11, empirical relationships can be employed to describe the trends of observation. Due to the concentrated nondimensional fetch, our observations appear to be very scattered.

Since the equilibrium range of the observed spectra starts at the peak frequencies (see Fig. 10), the maximum spectral density can be estimated by

$$
E\left(f_{p}\right)=\alpha \mathrm{Ws} g(2 \pi)^{-3} f_{p}^{-4}=A_{\alpha} \chi^{n_{H}-3 n_{f}} \operatorname{Ws} g(2 \pi)^{-3} f_{p}^{-4} .
$$

Compared with Eq. (8), we have

$$
\varepsilon_{\max }=\frac{g^{3} S\left(f_{p}\right)}{\mathrm{Ws}^{5}}=A_{s} \chi^{n_{H}-n_{f}} .
$$

Moreover, the following relationship between $\varepsilon_{\max }$ and $\varepsilon$ can be established:

$$
\varepsilon_{\max }=A_{H_{S}} \varepsilon^{-n_{H} / n_{f}}
$$

The validations presented in Fig. 12 (left and middle) show that $\varepsilon_{\max }$ can be accurately estimated by Eqs. (16) and (17). It is interesting that the empirical relationship between $\varepsilon_{\max }$ and $\varepsilon$ suits the observations more than Eqs. (13), (14), and (16).

Furthermore, it is found that $-n_{H} / n_{f}=1.05 / 0.8 \approx 5 / 4$, which results in

$$
S\left(f_{p}\right)=A_{H_{S}}^{\prime} g^{-1 / 2} H_{s}^{5 / 2} .
$$

The empirical relationship is also validated using our observations in Fig. 12 (right). The good agreement between the observations and Eq. (18) indicates that there is an internal drive that exists to balance the total energy and the maximum energy density of the waves.

\section{b. Leaving stage: Waves from the open sea}

Nondimensional spectra of waves at $\tau>0$ are given in Fig. 13. Compared with Fig. 10, the spectra in the leaving stage are steeper and more concentrated than those in the approaching stage in the prepeak region. Besides, four double-peak spectra are found in the leaving stage of Typhoon Talas. To remove the impact of the subpeaks, spectral densities at frequencies larger than $0.35 \mathrm{~Hz}$ are ignored for these four spectra.

In the leaving stage, both the energy densities in the pre and postpeak regions can be expressed in terms of the power law of frequency as follows:

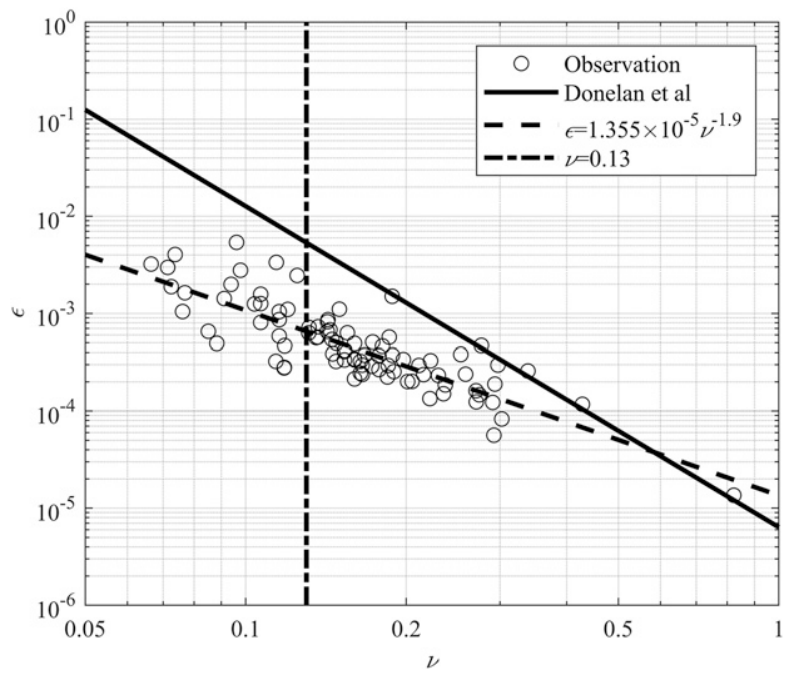

FIG. 9. Relationship between nondimensional energy and nondimensional peak frequency in the leaving stage. 

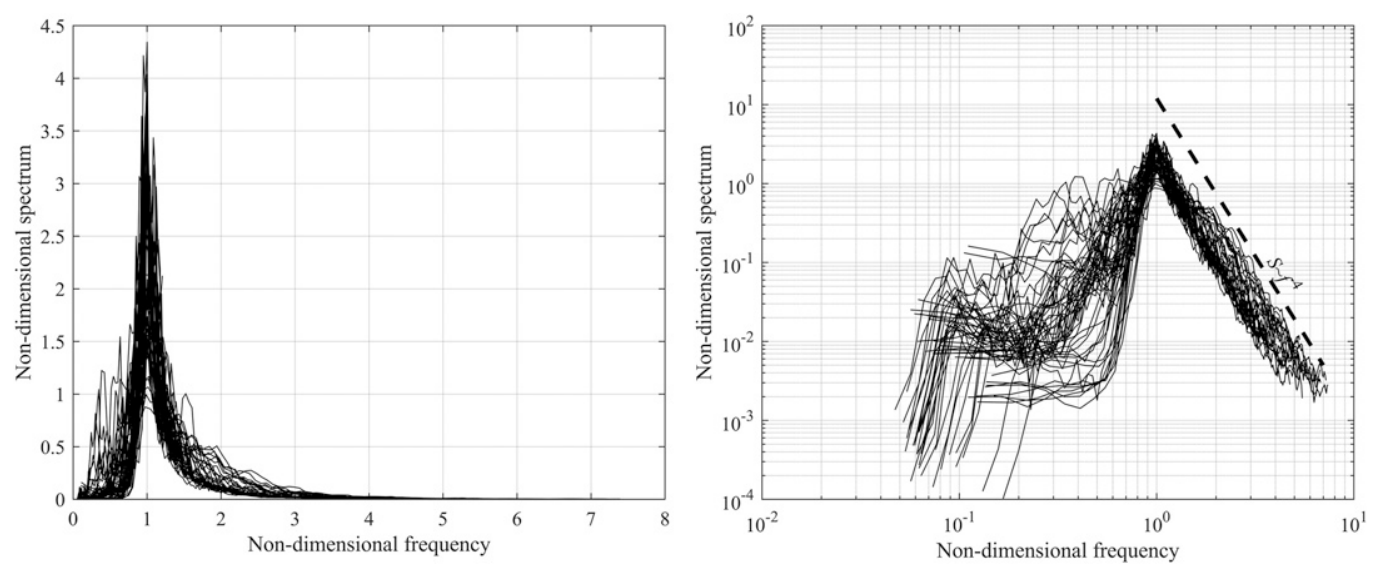

FIG. 10. Nondimensional spectra in the approaching stage.

$$
S(f)=a f_{p}^{-b+c} f^{b}, \quad b=\left\{\begin{array}{cc}
b_{f}, & f<f_{p} \\
-b_{a}, & f \geq f_{p}
\end{array} .\right.
$$

The fitting results of some cases and the distribution of correlations are presented in Fig. 14. More than $95 \%$ of correlations are larger than 0.9, indicating that Eq. (19) is suitable for our observations.

Inspired by Eqs. (11) and (17), the parameters $a$ and $c$ are found to be dependent on nondimensional peak frequency $\nu$, see Fig. 15 (left):

$$
\frac{a g^{c+3}}{\mathrm{Ws}^{c+5}}=8.511 \times 10^{-6} \nu^{-3.91} .
$$

Additionally, we validate the relationship between the maximum spectral density and $H_{s}$ for the waves in the leaving stage, see Fig. 15 (right):

$$
S\left(f_{p}\right)=1.897 g^{-1 / 2} H_{s}^{5 / 2}
$$

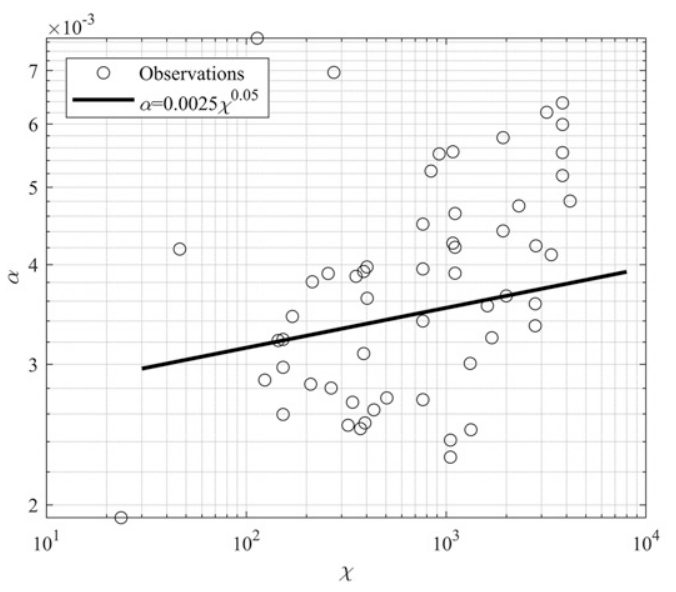

The results show that Eq. (18) is suitable for waves in the approaching and leaving stages with similar parameters.

Parameter $b_{f}$ is shown in Fig. 16 (left). The mean value of $b_{f}$ is 6 . The figures show that $b_{f}$ decreases with increasing peak frequency. On the other hand, the parameter $b_{a}$ increases with the peakness $P$, as shown in Fig. 16 (right), where

$$
P=\frac{f_{p} S\left(f_{p}\right)}{\int S(f) d f} .
$$

However, the distributions of $b_{f}$ and $b_{a}$ are so scattered that the solid lines in Fig. 16 represent only the general trends of these two parameters.

\section{Conclusions}

A series of observations of typhoon waves in a lagoon of the South China Sea is investigated to draw the following conclusions:

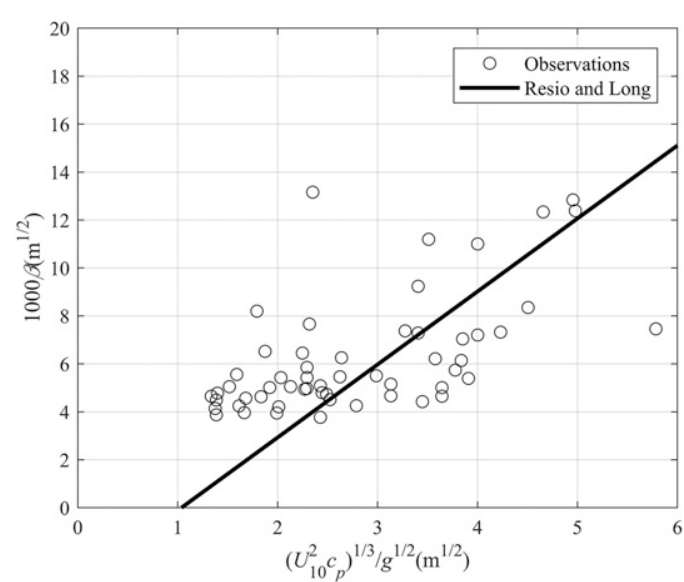

FIG. 11. Validation of empirical relationships between $\alpha$ and $\beta$. 

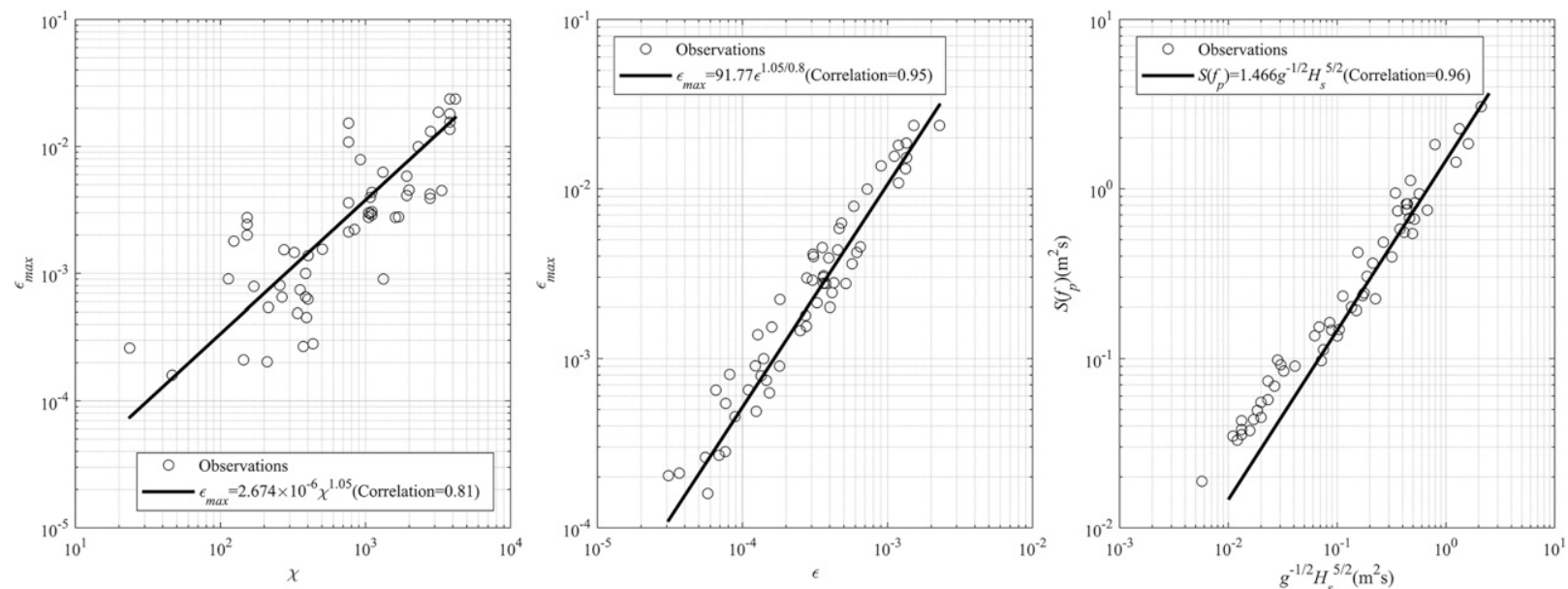

FIG. 12. Estimating $S\left(f_{p}\right)\left(\varepsilon_{\max }\right)$ by $\varepsilon, \chi$, and $H_{s}$. (left) Validation of the empirical relationship between $\varepsilon_{\max }$ and $\varepsilon$. (center) Validation of the empirical relationship between $\varepsilon_{\max }$ and $\chi$. (right) Validation of the empirical relationship between the maximum spectral density and $H_{s}$.

1) According to the upper boundaries of $H_{s}$ and wind speed, the maximum wave height has a similar rate of change as the maximum wind speed. Note that this result is limited by the data, which come from a small number of typhoons.

2) The evolution of typhoon waves in the lagoon can be divided into approaching and leaving stages. In the approaching stage, the peak frequencies are scattered and decrease with time. In addition, both the waves and winds came from the north, and the following waves dominated the field. In the leaving stage, the peak frequencies are concentrated, the average of which is $0.1415 \mathrm{~Hz}$, and most of these winds and waves came from the south and west, respectively. According to these results, wind waves generated inside the lagoon and waves from the open sea are common in the approaching and leaving stages, respectively.
3) Waves generated inside the lagoon are in remarkably good agreement with the fetch-limited theory. Analysis of the spectra shows that the equilibrium range starts from the peak frequency. In addition, a relationship between the nondimensional maximum spectral density and nondimensional fetch is established, which we suggest is a common relationship for fetch-limited waves.

4) For the waves from the open sea, the wave energy is overestimated by the fetch-limited theory. The spectra of these waves can be described by $a f_{p}^{(c-b)} f^{(b)}$, where $b=b_{f}$ and $b=b_{a}$ in the pre- and postpeak regions, respectively. Parameters $a$ and $c$ are linked to the nondimensional peak frequency. On the other hand, the parameter $b_{f}$ decreases with increasing peak frequency, and the parameter $b_{a}$ increases with the peakness $P$.
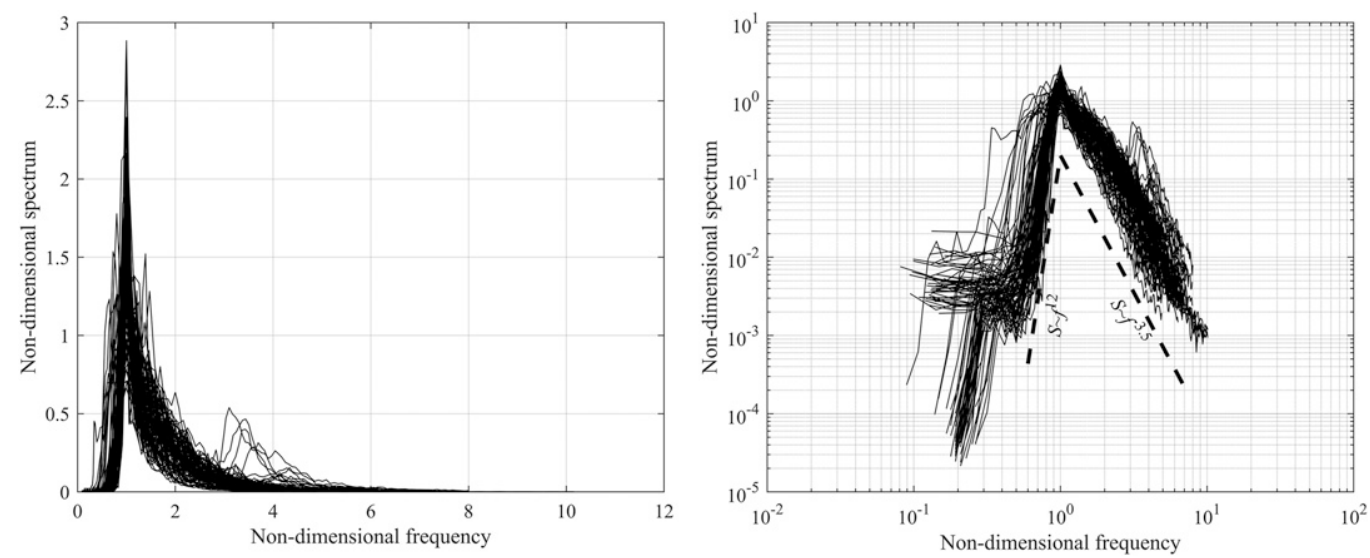

FIG. 13. Nondimensional spectra in the leaving stage. 

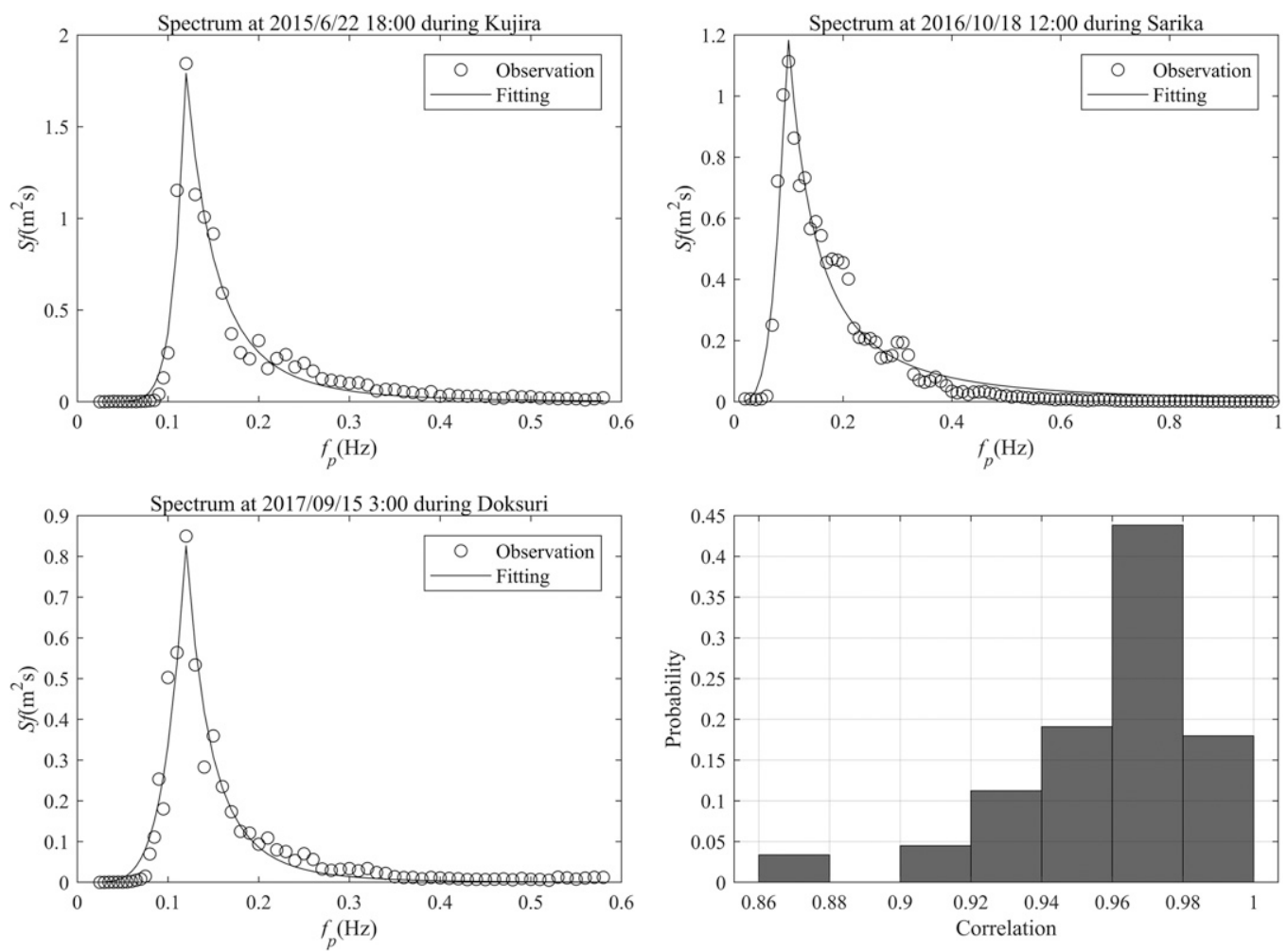

FIG. 14. The fitting results of three measured spectra and the distribution of correlations between the observed spectrum and fitting spectrum (shown at bottom right).

5) It is found that the peak energy density $S\left(f_{p}\right)$ is a linear function of $g^{-1 / 2} H_{s}^{5 / 2}$ for all typhoon waves, which indicates that there is an internal drive that exists to balance the total energy and the maximum energy density of the waves.

Because of the topography, the wave behavior in the lagoon is more complex than that in the open sea. As a result, there are some shortcomings we want to state for this paper:

1) Based on the distributions of wind and waves, it is found that waves generated inside and outside the lagoon propagated to the site in the approaching and leaving stages, respectively. However, it is not certain that this result can be extended to more general
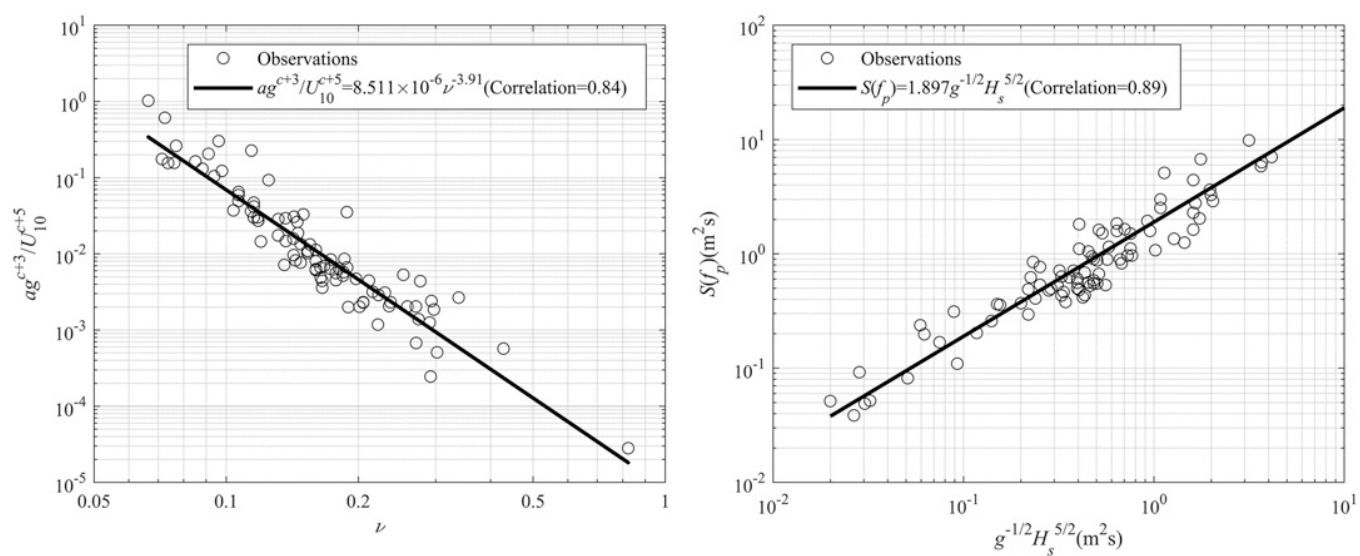

FIG. 15. Validation of the empirical relationships in the leaving stage. (left) Relationship between nondimensional $a$ and nondimensional peak frequency. (right) Relationship between $S\left(f_{p}\right)$ and $g^{-1 / 2} H_{s}^{5 / 2}$. 

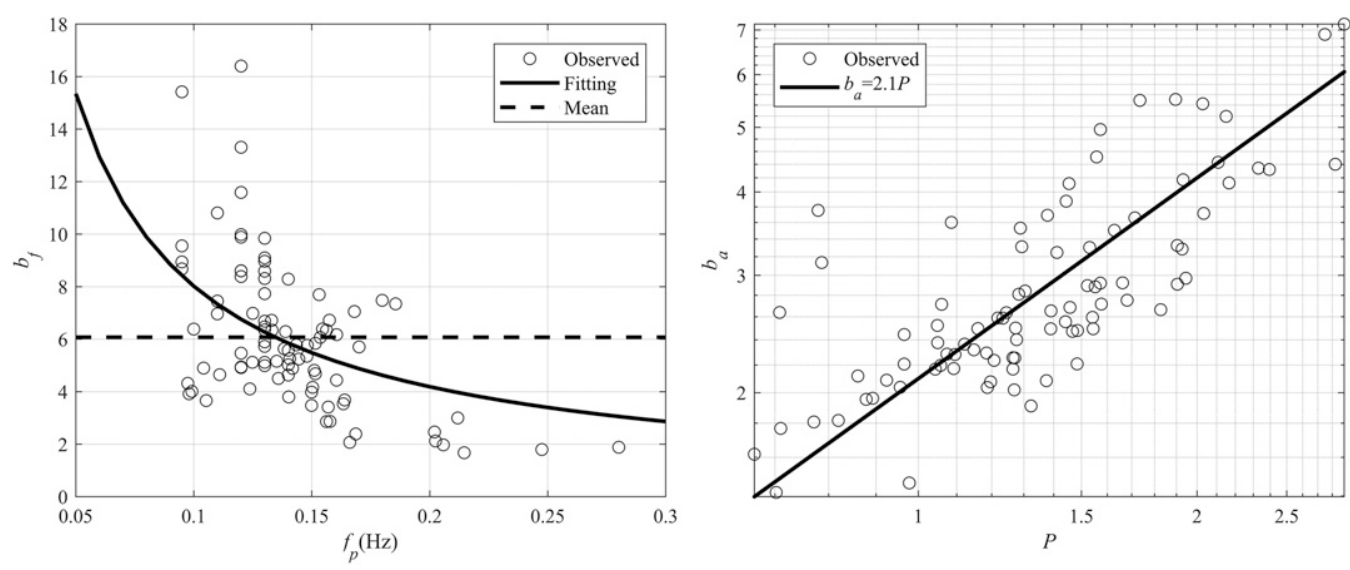

FIG. 16. Distributions of $b_{f}$ and $b_{a}$.

applications. In our opinion, this conclusion is heavily dependent on the local geometry and the tracks of typhoons.

2) In our opinion, the local wind waves are less sensitive to the stages as these waves are fetch-trapped. However, waves from the open sea are sensitive to the stages. Unfortunately, waves from the open sea that occurred in the approaching stage are neglected owing to limited measurement data.

Acknowledgments. This research was supported by the Ministry of Industry and Information Technology with the research project in the fields of high-tech ships under Grant [2016]22.

\section{REFERENCES}

Badulin, S. I., A. N. Pushkarev, D. T. Resio, and V. E. Zakharov, 2005: Self-similarity of wind-driven seas. Nonlinear Processes Geophys., 12, 891-945, https://doi.org/10.5194/npg-12-891-2005.

Black, P. G., and Coauthors, 2007: Air-sea exchange in hurricanes: Synthesis of Observations from the Coupled Boundary Layer Air-Sea Transfer Experiment. Bull. Amer. Meteor. Soc., 88, 357-374, https://doi.org/10.1175/BAMS-88-3-357.

Cai, Z., W. Chen, X. Liu, Z. Sun, C. Tian, and Q. Yun, 2019: Waves enter a reef lagoon with double barriers in South China Sea: In-situ measurement and simulation. Int. Ocean and Polar Engineering Conf., Honolulu, HI, International Society of Offshore and Polar Engineers, ISOPE-I-19-220, https://onepetro.org/conference-paper/ISOPE-I-19-220.

Cheriton, O. M., C. D. Storlazzi, and K. J. Rosenberger, 2016: Observations of wave transformation over a fringing coral reef and the importance of low-frequency waves and offshore water levels to runup, overwash, and coastal flooding. J. Geophys. Res. Oceans, 121, 3121-3140, https://doi.org/ 10.1002/2015JC011231.

Chu, P. C., and K. F. Cheng, 2008: South China Sea wave characteristics during typhoon Muifa passage in winter 2004. J. Oceanogr., 64, 1-21, https://doi.org/10.1007/s10872-008-0001-9.

—, Q. Qi, Y. C. Chen, P. Shi, and Q. W. Mao, 2004: South China Sea wind-wave characteristics. Part I: Validation of Wavewatch-III using TOPEX/Poseidon data. J. Atmos. Oceanic Technol., 21, 1718-1733, https://doi.org/10.1175/JTECH1661.1.

Datawell, 2006: Datawell Waverider reference manual: DWRMkIII, DWR-G, WR-SG. Datawell BV, 158 pp., http:// www.datawell.nl/Support/Documentation/Manuals.aspx.

Ding, J., C. Tian, Y. Wu, Z. Li, H. Ling, and X. Ma, 2017: Hydroelastic analysis and model tests of a single module VLFS deployed near islands and reefs. Ocean Eng., 144, 224 234, https://doi.org/10.1016/j.oceaneng.2017.08.043.

Donelan, M. A., J. Hamilton, and W. H. Hui, 1985: Directional spectra of wind-generated waves. Philos. Trans. Roy. Soc. London, 315A, 509-562, https://doi.org/10.1098/rsta.1985.0054.

Gallop, S. L., I. R. Young, R. Ranasinghe, T. H. Durrant, and I. D. Haigh, 2014: The large-scale influence of the Great Barrier Reef matrix on wave attenuation. Coral Reefs, 33, 1167-1178, https://doi.org/10.1007/s00338-014-1205-7.

Gourlay, M. R., 1994: Wave transformation on a coral reef. Coast. Eng., 23, 17-42, https://doi.org/10.1016/0378-3839(94)90013-2.

Herbers, T. H. C., R. J. Seymour, and R. T. Guza, 2009: A comparison of directional buoy and fixed platform measurements of Pacific swell. J. Atmos. Oceanic Technol., 13, 231-272, https:// doi.org/10.1175/1520-0426(1996)013<0231:ACODBA > 2.0.CO;2.

Holthuijsen, L. H., M. D. Powell, and J. D. Pietrzak, 2012: Wind and waves in extreme hurricanes. J. Geophys. Res., 117, C09003, https://doi.org/10.1029/2012JC007983.

Hong Kong Observatory, 2015: Tropical cyclones in 2014. Annual Rep., 118 pp., https://www.hko.gov.hk/tc/publica/tc/files/TC2014.pdf.

Huang, Z. C., L. Lenain, W. K. Melville, J. H. Middleton, B. Reineman, N. Statom, and R. M. McCabe, 2012: Dissipation of wave energy and turbulence in a shallow coral reef lagoon. J. Geophys. Res., 117, C03015, https://doi.org/10.1029/2011JC007202.

Hwang, P. A., 2016: Fetch- and duration-limited nature of surface wave growth inside tropical cyclones: With applications to airsea exchange and remote sensing. J. Phys. Oceanogr., 46, 4156, https://doi.org/10.1175/JPO-D-15-0173.1.

— and D. W. Wang, 2004: Field measurements of duration-limited growth of wind-generated ocean surface waves at young stage of development. J. Phys. Oceanogr., 34, 2316-2326, https://doi.org/ 10.1175/1520-0485(2004)034<2316:FMODGO>2.0.CO;2.

—_ , and E. J. Walsh, 2016: Azimuthal and radial variation of wind-generated surface waves inside tropical cyclones. J. Phys. Oceanogr., 46, 2605-2621, https://doi.org/10.1175/JPO-D-16-0051.1.

- and Y. Fan, 2017: Effective fetch and duration of tropical cyclone wind fields estimated from simultaneous wind and 
wave measurements: Surface wave and air-sea exchange computation. J. Phys. Oceanogr., 47, 447-470, https://doi.org/ 10.1175/JPO-D-16-0180.1.

,-- , F. J. Ocampo-Torres, and H. García-Nava, 2017: Ocean surface wave spectra inside tropical cyclones. J. Phys. Oceanogr. 47, 2393-2417, https://doi.org/10.1175/JPO-D-17-0066.1.

Kench, P. S., and R. W. Brander, 2006: Wave processes on coral reef flats: Implications for reef geomorphology using Australian case studies. J. Coastal Res., 221, 209-223, https://doi.org/10.2112/ 05A-0016.1.

King, D. B., and O. H. Shemdin, 1978: Radar observations of hurricane wave directions. 16th Int. Conf. on Coastal Engineering, Hamburg, Germany, ASCE, https://doi.org/ 10.1061/9780872621909.012.

Lentz, S. J., J. H. Churchill, K. A. Davis, and J. T. Farrar, 2016: Surface gravity wave transformation across a platform coral reef in the Red Sea. J. Geophys. Res. Oceans, 121, 693-705, https://doi.org/10.1002/2015JC011142.

Liu, X., W. Chen, Z. Cai, Z. Sun, C. Tian, and Q. Yun, 2019: Investigation on wave attenuation due to bottom friction of sea bed by in-situ measurement. Int. Ocean and Polar Engineering Conf., Honolulu, HI, International Society of Offshore and Polar Engineers, ISOPE-I-19-231, https:// onepetro.org/conference-paper/ISOPE-I-19-231.

Lohrmann, A., T. Pedersen, S. Nylund, and E. Siegel, 2011: Waves in the summer ice in the winter. 10th Current, Waves and Turbulence Measurements Conf., Monterey, CA, IEE, https:// doi.org/10.1109/CWTM.2011.5759544.

Long, C. E., and D. T. Resio, 2007: Wind wave spectral observations in Currituck Sound, North Carolina. J. Geophys. Res., 112, C05001, https://doi.org/10.1029/2006JC003835.

Lowe, R. J., J. L. Falter, M. D. Bandet, G. Pawlak, M. J. Atkinson, S. G. Monismith, and J. R. Koseff, 2005: Spectral wave dissipation over a barrier reef. J. Geophys. Res., 110, C04001, https://doi.org/10.1029/2004JC002711.

Luther, M. E., G. Meadows, E. Buckley, S. A. Gilbert, H. Purcell, and M. N. Tamburri, 2013: Verification of wave measurement systems. Mar. Technol. Soc. J., 47, 104-116, https://doi.org/ 10.4031/MTSJ.47.5.11.

Monismith, S. G., L. M. M. Herdman, S. Ahmerkamp, and J. L. Hench, 2013: Wave transformation and wave-driven flow across a steep coral reef. J. Phys. Oceanogr., 43, 1356-1379, https://doi.org/10.1175/JPO-D-12-0164.1.

_ J. S. Rogers, D. Koweek, and R. B. Dunbar, 2015: Frictional wave dissipation on a remarkably rough reef. Geophys. Res. Lett., 42, 4063-4071, https://doi.org/10.1002/2015GL063804.

Pedersen, T., and A. Lohrmann, 2004: Possibilities and limitations of acoustic surface tracking. Oceans '04 MTS/IEEE Techno-Ocean, Kobe, Japan, IEEE, https://doi.org/10.1109/ OCEANS.2004.1406331.

_ E. Siegel, and J. Wood, 2006: Directional wave measurements from a subsurface buoy with an acoustic wave and current profiler (AWAC). OCEANS 2007, Vancouver, BC, Canada, IEEE, https://doi.org/10.1109/OCEANS.2007.4449153.

Péquignet, A. C., J. M. Becker, M. A. Merrifield, and S. J. Boc, 2011: The dissipation of wind wave energy across a fringing reef at Ipan, Guam. Coral Reefs, 30, 71-82, https://doi.org/ 10.1007/s00338-011-0719-5.

Powell, M. D., 2007: Drag coefficient distribution and wind speed dependence in tropical cyclones. Final Rep. to the NOAA Joint Hurricane Testbed Program, 26 pp., https://www.nhc.noaa.gov/ jht/05-07reports/final_Powell_JHT07.pdf.
Ren, X., B. Xie, and Z. Song, 2014: Statistical characteristics of the double-peaked wave spectra in the deep area of the South China Sea (in Chinese). Adv. Mar. Sci., 32, 148-154.

Resio, D. T., C. E. Long, and C. L. Vincent, 2004: Equilibriumrange constant in wind-generated wave spectra. J. Geophys. Res., 109, C01018, https://doi.org/10.1029/2003JC001788.

Shi, H., X. Cao, X. Wen, M. Shi, D. Zhao, and P. Guo, 2017: The research on typhoon wave spectrum in northwestern South China Sea. J. Ocean Univ. China, 16, 8-14, https://doi.org/ 10.1007/s11802-017-3115-0.

Smith, A., N. Lott, and R. Vose, 2011: The integrated surface database: Recent developments and partnerships. Bull. Amer. Meteor. Soc., 92, 704-708, https://doi.org/10.1175/2011BAMS3015.1.

Smith, H. C. M., D. Haverson, and G. H. Smith, 2013: A wave energy resource assessment case study: Review, analysis and lessons learnt. Renew. Energy, 60, 510-521, https://doi.org/ 10.1016/j.renene.2013.05.017.

Sun, Z., X. Liu, Z. Cai, J.-G. Li, W. Chen, J. Ding, and C. Tian, 2019: A comparison of WAVEWATCH III grid models for a typical reef lagoon. Int. Ocean and Polar Engineering Conf., Honolulu, HI, International Society of Offshore and Polar Engineers, ISOPE-I-19-227, https://onepetro.org/conferencepaper/ISOPE-I-19-227.

Tannehill, I. R., 1936: Sea swells in relation to movement and intensity of tropical storms. Mon. Wea. Rev., 64, 231-238, https:// doi.org/10.1175/1520-0493(1936)64<231b:SSIRTM>2.0.CO;2.

Wright, C. W., E. J. Walsh, D. Vandemark, W. B. Krabill, and A. W. Garcia, 2001: Hurricane directional wave spectrum spatial variation in the open ocean. J. Phys. Oceanogr., 31, 2472-2488, https://doi.org/10.1175/1520-0485(2001)031<2472: HDWSSV $>2.0 . \mathrm{CO} ; 2$.

Wu, Y. S., J. Ding, C. Tian, Z. W. Li, H. J. Ling, X. Z. Ma, and J. L. Gao, 2018: Numerical analysis and model tests of a threemodule VLFS deployed near islands and reefs. J. Ocean Eng. Mar. Energy, 4, 111-112, https://doi.org/10.1007/s40722-0180112-3.

Xu, Y., H. He, J. Song, Y. Hou, and F. Li, 2017: Observations and modeling of typhoon waves in the South China Sea. J. Phys. Oceanogr., 47, 1307-1324, https://doi.org/10.1175/JPO-D-160174.1 .

Young, I., 1988: Parametric hurricane wave prediction model. J. Waterw. Port Coast. Ocean Eng., 114, 637-652, https:// doi.org/10.1061/(ASCE)0733-950X(1988)114:5(637).

- 1998: Observations of the spectra of hurricane generated waves. Ocean Eng., 25, 261-276, https://doi.org/10.1016/S00298018(97)00011-5.

_ 1999: Wind Generated Ocean Waves. Elsevier Science, 314 pp. 2006: Directional spectra of hurricane wind waves. J. Geophys. Res., 111, C08020, https://doi.org/10.1029/2006JC003540.

- 2017: A review of parametric descriptions of tropical cyclone wind-wave generation. Atmosphere, 8, 194, https://doi.org/ 10.3390/atmos8100194.

, and J. Vinoth, 2013: An extended fetch model for the spatial distribution of tropical cyclone wind-waves as observed by altimeter. Ocean Eng., 70, 14-24, https://doi.org/ 10.1016/j.oceaneng.2013.05.015.

Zakharov, V. E., D. Resio, and A. Pushkarev, 2012: New wind input term consistent with experimental, theoretical and numerical considerations. arXiv, https://arxiv.org/abs/1212.1069.

Zhang, J. A., and E. W. Uhlhorn, 2012: Hurricane sea surface inflow angle and an observation-based parametric model. Mon. Wea. Rev., 140, 3587-3605, https://doi.org/10.1175/MWR-D11-00339.1. 


\title{
CORRIGENDUM
}

\author{
Z. W. CAI \\ Department of Offshore Structures, China Ship Scientific Research Center, Wuxi, and Southern Marine Science \\ and Engineering Guangdong Laboratory, Zhanjiang, China \\ W. W. CHEN \\ Shanghai Branch, China Ship Scientific Research Center, Shanghai, and Southern Marine Science, Shanghai, \\ and Engineering Guangdong Laboratory, Zhanjiang, China

\section{L. LIU AND Z. SUN} \\ Department of Offshore Structures, China Ship Scientific Research Center, Wuxi, and Southern Marine Science \\ and Engineering Guangdong Laboratory, Zhanjiang, China
}

(Manuscript received 31 January 2020, in final form 5 March 2020)

In our original article (Cai et al. 2020), the sign before $3 n_{f}$ of Eq. (13) was incorrect. What appears below is the correct version:

$$
\alpha=A_{\alpha} \chi^{n_{H}+3 n_{f}} .
$$

This correction does not affect the following content and the reported results as originally published.

In addition, Eq. (17) was also incorrect. What appears below is the correct version:

$$
\varepsilon_{\max }=A_{H_{S}} \varepsilon^{\frac{n_{H}-n_{f}}{n_{H}}} .
$$

The discussion following the equations on p. 168 [before Eq. (18)], "Furthermore, it is found that $-n_{H} / n_{f}=1.05 / 0.8 \approx 5 / 4$ " should be revised as "Furthermore, it is found that $\left(n_{H}-n_{f}\right) / n_{H}=1.05 / 0.8 \approx 5 / 4$." These corrections do not affect the reported results as originally published.

\section{REFERENCE}

Cai, Z. W., W. W. Chen, X. L. Liu, and Z. Sun, 2020: Observations of typhoon waves in a reef lagoon of the South China Sea. J. Phys. Oceanogr., 50, 161-173, https://doi.org/10.1175/JPO-D-19-0146.1.

Corresponding author: Z. W. Cai, caizhiwen0904@163.com 